\title{
Tinjauan Perencanaan Spillway Bendungan Karalloe di Kabupaten Gowa
}

\author{
Nataniel Yunus Alik*1 Melly Lukman*2 Benyamin Tanan*3 \\ *1 Mahasiswa Program Studi Teknik Sipil, Universitas Kristen Indonesia Paulus, Makassar, Indonesia \\ niel.nael2198@gmail.com \\ *2,3 Dosen Program Studi Teknik Sipil, Universitas Kristen Indonesia Paulus, Makassar, Indonesia \\ mellylukman@yahoo.com dan nyamintan2002@yahoo.com
}

\begin{abstract}
ABSTRAK
Penelitian ini membahas tentang tinjauan perencanaan Spillway pada proyek Bendungan Karalloe. Spillway tersebut berfungsi untuk mengalirkan air yang berlebihan dari bendungan agar tidak terjadi overtopping pada bendungan kembali ke sungai. Digunakan tiga metode dalam perhitungan analisa curah hujan yaitu Metode Gumbel, Log Pearson Tipe III, dan Log Normal. Debit banjir rancangan dianalisis menggunakan Metode Hidrograf Satuan Sintesis Gama-I. Perencanaan Spillway direncanakan berdasarkan perbedaan debit banjir rancangan dan tipe mercu Spillway. Hasil penelitian ini didapatkan debit banjir rancangan sebesar $613,251 \mathrm{~m}^{3} / \mathrm{det}$ dan tinggi energi di atas mercu sebesar 2,902 $\mathrm{m}$ dengan menggunakan tipe mercu bulat.
\end{abstract}

Kata Kunci : Banjir, Perencanaan Spillway, Mercu, Tinggi energi

\begin{abstract}
This study discusses the review of Spillway planning in the Karalloe Dam project. The spillway serves to drain excess water from the dam to avoid overtopping the dam back to the river. Three methods are used in the calculation of rainfall analysis, namely the Gumbel Method, Pearson Log Type III, and Normal Log. Design flood discharge was analyzed using the Gama-I Synthesis Unit Hydrograph Method. Spillway planning is planned based on differences in design flood discharge and Spillway lighthouse type. The results of this study obtained a design flood discharge of $613,251 \mathrm{~m} 3 / \mathrm{sec}$ and high energy above the lighthouse of 2,902 $\mathrm{m}$ using the type of round lighthouse.
\end{abstract}

Keywords: flood, spillway, lighthouse, high energy 


\section{PENDAHULUAN}

Banjir merupakan suatu fenomena alam yang dapat menimbulkan kerugian besar bagi manusia. Banjir dapat terjadi karena luapan air sungai, waduk, danau, laut, atau badan air lainnya yang menggenangi dataran rendah dan cekungan yang awalnya tergenang. Banjir dapat terjadi setiap kejadian hujan , musih hujan, atau beberapa kali musim hujan. Banjir tidak sepenuhnya disebabkan oleh faktor alam melainkan disebabkan oleh perilaku manusia. Salah satu upaya untuk pengendalian banjir adalah dengan membangun bendungan. Bendungan adalah suatu kontruksi yang dibuat agar mampu menampung air yang berlebihan sehingga dapat menanggulangi masalah banjir. Bendungan selalu dilengkapi dengan Spillway atau bangunan pelimpah. Bangunan pelimpah atau Spillway adalah salah satu struktur yang dibangun sebagai salah satu bangunan pada Bendungan. Spillway berfungsi untuk melimpahkan debit air yang dianggap berlebihan kembali ke sungai agar tidak membahayakan bendungan terhadap overtopping. Spillway selain terdapat pada bendungan, dapat pula digunakan sebagai pelengkap utama pada bendung. Dengan adanya Spillway, elevasi muka air di hulu didesain tidak akan melampaui batas maksimum berkaitan dengan debit banjir rencana. Ada beberapa tipe Spillway yang sering ditemui, salah satunya adalah Bangunan Pelimpah Samping atau Side Channel Spillway. Spillway ini terletak pada bagian hulu dan di sisi bendungan. Air mengalir melewati saluran samping kemudian mengalir turun meluncur langsung ke sungai. Pada Bendungan Karalloe dibangun satu unit bangunan pelimpah atau Spillway dengan menggunakan tipe pelimpah samping.

Pada tanggal 22 Januari 2019 terjadi banjir di Bendungan Karalloe. Banjir ini mengakibatkan air dari sungai Kelara mampu melewati Coffer Dam yang dibuat untuk menahan air sehingga air tidak masuk ke lokasi proyek. Hal ini terjadi dikarenakan tidak tepatnya debit rancangan yang telah dibuat sebelumnya. Maka dari itu penulis ingin membuat suatu peninjauan kembali terhadap salah satu kontruksi pelengkap bendungan yang fungsinya juga sangat penting yaitu Spillway atau bangunan pelimpah untuk mengidentifikasi ulang apakah debit rancangan sebelumnya sudah tepat atau perlu peninjauan kembali.

\section{Bangunan Pelimpah ( Spillway)}

Bangunan Pelimpah (Spillway) adalah bangunan beserta instalasinya untuk mengalirkan air banjir yang masuk ke dalam waduk agar tidak membahayakan keamanan bendungan. Apabila terjadi kecepatan aliran yang besar akan terjadi olakan (turbulensi) yang dapat mengganggu jalannya air sehingga menyebabkan berkurangnya aliran air yang masuk ke bangunan pelimpah. Maka kecepatan aliran air harus dibatasi, yaitu tidak melebihi kecepatan kritisnya. Ukuran bangunan pelimpah harus dihitung dengan sebaik - baiknya, karena kalau terlalu kecil ada risiko tidak mampu melimpahkan debit air banjir yang terjadi.

\section{Analisis Hidrologi}

Analisis hidrologi adalah kumpulan keterangan atau fakta mengenai fenomena hidrologi. Fenomena hidrologi seperti besarnya curah hujan, temperatur, penguapan, lamanya penyinaran matahari, kecepatan angin, debit sungai, tinggi muka air, selalu berubah menurut waktu.

Dalam penelitian ini digunakan beberapa data curah hujan diantaranya adalah data curah hujan rata - rata wilayah, kemudian untuk data curah hujan tahunan,bulanan, dan harian maksimum akan dicari dengan menggunakan data dari stasiun hujan yang terdekat dari lokasi proyek Bendungan Karalloe setelah itu dikelolah menjadi data curah hujan rata rata, untuk itu digunakan empat macam distribusi dalam bidang hidrologi yaitu Distribusi Normal, Distribusi Log Normal, Distribusi Gumbel, Distribusi Log Pearson Type III.

\section{Curah Hujan Rata-Rata}

Data curah hujan rata - rata digunakan sebagai pendukung dalam perhitungan curah hujan harian maksimum dapat dihitung menggunakan metode Poligon Thiessen .

\section{Metode Poligon Thiessen}

Metode Poligon Thiessen ini bisa digunakan untuk daerah - daerah di mana distribusi dari pengamat hujan tidak tersebar merata. Hasilnya lebih teliti. Caranya :

a. Stasiun pengamat digambar pada peta, dan ditarik garis hubungan masing - masing stasiun.

b. Garis bagi tegak lurus dari garis hubung tersebut membentuk poligon - poligon mengelilingi tiap - tiap stasiun, hidari bentuk polligon segitiga tumpul.

c. Sisi tiap polygon merupakan batas - batas daerah pengamat hujan y.b.s.

d. Hitung luas tiap polygon yang terdapat di dalam D.A.S dan luas D.A.S seluruhnya, dengan planimeter, dan luas tiap polygon dinyatakan sebagai persentasi dari luas D.A.S. seluruhnya.

e. Faktor bobot dalam menghitung hujan rata rata daerah di dapat dengan mengalikan presipitasi tiap stasiun pengamat dikalikan dengan presentasi luas daerah.

f. Hujan rata -rata daerah. 


\section{Curah Hujan maksimum}

Dari hasil curah hujan rata-rata yang telah didapatkan selanjutnya akan ditentukan curah hujan maksimum untuk setiap tahun.

\section{Curah Hujan Rancangan}

Dari hasil perhitungan curah hujan rata-rata maksimum dengan Metode Poligon Thiessen di atas perlu ditentukan kemungkinan terulangnya curah hujan bulanan maksimum guna menentukan debit banjir rencana.

\section{Uji Kesesuaian Distribusi}

Masing-masing distribusi memiliki sifat yang khas, sehingga data curah hujan harus diuji kesesuaiannya terhadap sifat statistik masing-masing distribusi tersebut. Untuk mengetahui apakah jenis distribusi curah hujan yang dipilih dalam perhitungan curah hujan dapat diterima atau ditolak, maka perlu dilakukan uji kesesuaian distribusi.

Uji Smirnov Kolmogorof Uji kesesuaian dengan metode Smirnov Kolmogorof digunakan untuk menguji simpangan baku dengan cara horizontal, yaitu mencari selisih simpangan maksimum antara distribusi teoritis dengan distribusi empiris (Do).

Uji kesesuaian dilakukan dengan tahapan sebagai berikut :

a. Data diurutkan dan tentukan besar peluangnya masingmasing $(\mathrm{Px})$.

b. Ditentukan nilai masing-masing peluang teoritis (Sn)

c. Dari kedua nilai peluang tersebut tentukan selisih terbesarnya antara peluang pengamatan dengan peluang teoritis $\Delta$ hit.

d. Berdasarkan nilai kritis (SmirnovKolmogorov test) tentukan harga $\Delta \mathrm{cr}$ Apabila $\Delta$ hit lebih kecil dari $\Delta c r$ maka distribusi teoritis yang digunakan untuk menentukan persamaan distribusi dapat diterima, apabila $\Delta$ hit lebih besar dari $\Delta c r$ maka distribusi teoritis yang digunakan untuk menentukan persamaan distribusi tidak dapat diterima.

Uji Chi-Square digunakan untuk menguji simpangan secara vertikal, apakah distribusi yang dipilih dapat diterima atau ditolak. Pada pengujian metode Smirnov Kolmogorof, walaupun menggunakan perhitungan matematis namun kesimpulan hanya berdasarkan sebuah variantyang mempunyai penyimpangan tersebar, sedangkan pengujian dengan metode ChiSquare menguji penyimpangan distribusi secara matematis kedekatan antara data pengamatan dan seluruh bagian garis persamaan teoritisnya.

Nilai $X^{2}$ yang terdapat ini harus lebih kecil dari harga $\mathrm{X}^{2} \mathrm{cr}$ (Kai-Kuadrat Kritis) pada tabel 2.8, untuk suatu derajat nyata tertentu (level of significance), yang sering diambil sebesar $5 \%$.

\section{Analisis Banjir Rancangan}

Banjir rancangan adalah besarnya debit banjir yang ditetapkan sebagai dasar banjir yang ditetapkan sebagai dasar penentuan kapasitas dan mendimensi penentuan kapasitas dan mendimensi bangunanbangunan hidraulik (termasuk bangunan hidraulik (termasuk bangunan di sungai), sedemikian hingga bangunan di sungai), sedemikian hingga kerusakan yang dapat ditimbulkan baik kerusakan yang dapat ditimbulkan baik langsung maupun tidak langsung oleh langsung maupun tidak langsung oleh banjir tidak boleh terjadi selama besaran banjir tidak boleh terjadi selama besaran banjir tidak terlampaui.

Perhitungan debit rancangan ini bertujuan untuk menghitung debit sungai kelara yang berada tepat dilokasi penelitian.

Berikut tahapan perhitungan banjir rancangan ini :

a. Pemilihan stasion curah hujan di sekitar lokasi studi.

b. Penentuan curah hujan harian maksimum

c. Analisa frekuensi untuk perhitungan curah hujan rencana

d. Debit banjir rancangan

Banjir Rancangan ini akan dihitung menggunakan metode Hidrograf Satuan Sintetik Gama-1.

Hidrograf Satuan Sintetik Gama I dikembangkan oleh Sri Harto (1993) berdasar perilaku hidrologis 30 DAS di Pulau Jawa. Meskipun diturunkan dari data DAS di Pulau Jawa, ternyata hidrograf satuan sintetis Gama I berfungsi baik untuk berbagai daerah lain di Indonesia.

HSS Gama I terdiri dari empat variabel pokok, yaitu naik (time of rise - TR), debit puncak $\left(Q_{p}\right)$, waktu dasar $(T B)$,dan sisi resesi yang ditentukan oleh nilai koefisien tampungan $(K)$.

\section{Pelimpah (spillway)}

Secara umum, panjang pelimpah direncanakan sepanjang mungkin, jika secara topografi dan secara ekonomi memungkinkan. Panjang pelimpah dalam hal ini ditentukan oleh rencana kapasitas tampungan waduk dan besarnya pemotongan debit puncak banjir rencana. (Persero PT. NINDYA KARYA).

Pelimpah diharapkan mampu menyadap debit banjir yang melebihi kapasitas maksimum sungai untuk ditampung dalam waduk dan sebaliknya melimpahkan air kembali ke sungai pada saat muka air sungai telah surut. Kondisi ini didasarkan pada skala.

Beberapa penelitian sejenis yaitu Dany et al melakukan pengkajian lebar bangunan pelimpah tipe 
lengkung terhadap elevasi muka banjir. Hasil kajian dengan menggunakan debit banjir 100 tahunan lebar spillway dengan elevasi crest $+20 \mathrm{~m}$ dan tinggi spillway $2 \mathrm{~m}$ [1].

Jalaludin et.al merencanakan pelimpah Bendungan Loea. Hasil perencanaan pembetonan dan penulangan pada konstruksi mercu pelimpah dan dinding penahan direncanakan dengan mutu beton f'c = $30 \mathrm{MPa}$ dan fy = $300 \mathrm{MPa}$ [2].

Saleh et.al melakukan kajian untuk mengetahui karakteristik aliran, pola aliran dan energy spesifik yang terjadi pada bangunan. Hasil penelitian pola aliran pada daerah hulu merupakan aliran sub kritis (FR1) kemudian menjadi kritis (FR $=1$ ) pada saat melewati bangunan pelimpah. Setelah melewati bangunan pelimpah maka aliran menjadi super kritis (FR 1) dan berangsur-angsur menjadi normal kembali pada saat berada di daerah hilir [3].

Putra dan Kumala dalam penelitian evaluasi kapasitas spillway Bendungan Darma dengan hasil aat terjadi banjir PMF, bendungan mengalami overtopping karena menurut SNI batas maksimal banjir yang boleh terjadi adalah 0,75 di bawah puncak mercu bendungan [4].

\section{METODOLOGI PENELITIAN}

\section{Lokasi dan Waktu Penelitian}

Lokasi penelitian adalah Bendungan Karraloe yang terletak di Kabupaten Gowa, Provinsi Sulawesi Selatan.

\section{Tahap Pengumupulan Data}

Adapun beberapa tahapan persiapan sebelum penelitian ini diantaranya :

a. Mempelajari serta menganalisa dokumen yang sudah ada dari konsultan dalam hal ini PT. Graha Asana.

b. Mempelajari beberapa literatur yang ada kaitannya dengan penelitian ini.

Dalam penelitian dibutukan data - data sebagai berikut :

a. Data curah hujan harian yang didapatkan dari Balai Besar Wilayah Sungai Pompengan Jeneberang.

b. Peta topografi yang diperoleh dari Global Mapper dan dokumendokumen yang sudah ada.

c. Peta tata guna lahan yang diperoleh dari Google Earth dan dokumendokumen yang sudah ada.

\section{Teknik Analisis Data}

a. Data Curah Hujan

Data curah hujan diperoleh dari beberapa stasiun yang terdekat dari lokasi penelitian. Berdasarkan peninjauan lapangan ada 3 stasiun hujan yang dekat dengan lokasi penelitian. Data curah hujan yang digunakan dapat dilihat pada tabel 1.

Tabel 1. Tabel stasiun hujan

\begin{tabular}{|c|c|c|c|c|c|}
\hline No & Stasiun & LS & BT & Jenis & $\begin{array}{c}\text { Seria } \\
\text { I } \\
\text { Data }\end{array}$ \\
\hline 1 & Malakaji & $05^{0} 25^{\prime} 45^{\prime \prime}$ & $\begin{array}{l}119^{0} 50^{\prime} 31 \\
\text { " }\end{array}$ & $\begin{array}{l}\text { Manua } \\
\text { I }\end{array}$ & $\begin{array}{l}1992 \\
\text { s/d } \\
2018\end{array}$ \\
\hline 2 & Sanrobone & $05^{0} 31^{\prime} 21^{\prime \prime}$ & $119^{\circ} 49^{\prime} 00$ & $\begin{array}{l}\text { Manua } \\
\text { I }\end{array}$ & $\begin{array}{l}1992 \\
\text { s/d } \\
2018\end{array}$ \\
\hline 3 & Paladingan & $\begin{array}{l}05^{0} 27^{\prime} 40,9 \\
\text { " }\end{array}$ & $119^{0} 49^{\prime} 31$ & $\begin{array}{l}\text { Manua } \\
\text { I }\end{array}$ & $\begin{array}{l}1992 \\
\text { s/d } \\
2018\end{array}$ \\
\hline
\end{tabular}

Setelah didapatkan beberapa stasiun terdekat dari lokasi penelitian selanjutnya akan dilakukan pengolahan dan analisa data curah hujan. Pertama mencari curah hujan rata - rata, dapat ditentukan dengan metode Thiessen.

Tahap berikutnya yaitu mencari tinggi hujan rencana atau analisis frekuensi dengan melakukan distribusi curah hujan. Distribusi curah hujan didapatkan dengan menggunakan tiga macam metode yaitu Distribusi Log Normal, Metode Gumbell, dan Metode Log Pearson tipe III.

Data yang hendak dianalisis sebaiknya dicoba dihitung dengan banyak persamaan distribusi untuk selanjutnya dengan uji statistik ditentukan persamaan distribusi yang paling sesuai dengan data tersebut (Uji Kesesuaian).

Uji kesesuaian distribusi dilakukan dengan menggunakan metode Smirnov-Kolmogorov dan Chisquare dua metode ini sering digunakan dalam pengujian kesesuain distribusi.

b. Data Peta Topografi

Data Peta topografi didapatkan dari data software BBWS Pompengan Jeneberang Makassar, dari data catchment area yang telah didapatkan kemudian ditentukan tiga stasiun terdekat dari lokasi penelitian menggunakan apilkasi AutoCAD.

\section{c. Data Penggunaan Lahan}

Data tata guna lahan didapatkan dari arsip BBWS Pompengan Jeneberang Makassar, dari data yang telah didapatkan dapat ditentukan nilai koefisien limpasan yang diperlukan dalam perhitungan debit rancangan.

\section{d. Data Bendungan}

Data bendungan didapatkan dari BBWS Pompengan Jeneberang Makassar, adapun data yang dibutuhkan antara lain elevasi genangan, elevasi mercu pelimpah,dimensi pelimpah serta luas genangan (waduk).

e. Analisis Debit Banjir Rancangan 
Analisa debit banjir rancangan dihitung menggunakan metode Hidrograf Satuan Sintetik Gama-1.

\section{f. Perencanaan Spillway}

Pada perencanaan Spillway digunakan dimensi pada perencanaan sebelumnya seperti lebar spillway, tinggi mercu,tinggi energy di atas mercu serta jari - jari pada mercu kemudian dicoba menggunakan tipe mercu yang berbeda dengan perencanan sebelumnya.

\section{ANALISIS DAN PEMBAHASAN}

\section{Analisa Hidrologi}

Dari tiga stasiun hujan yang didapatkan yaitu Malakaji, Sanrobone dan Palladingan selanjutnya diplot sehingga didapatkan polygon thiessen pada catchment area, setelah itu dihitung luas masing masing area stasiun. Catchment area dan polygon Thiessen dapat dilihat pada Gambar 2. Setelah dibuat polygon thiessen, selanjutnya tiap tiap daerah tangkapan sungai dari masing - masing stasiun dihitung luasnya menngunakan aplikasi AutoCAD. Luas daerah tangkapan dapat dilihat pada Tabel 2.

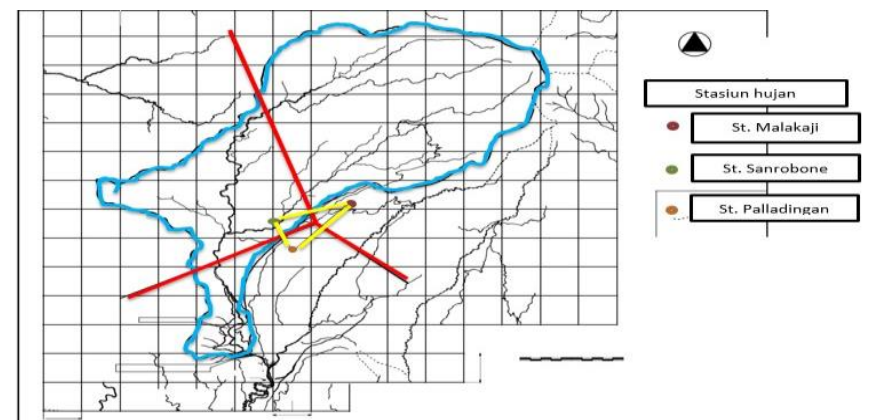

Gambar 2. Catchment Area dan Polygon Thiessen

Tabel 2. Hasil perhitungan Catchment Area dan Polygon Thiessen

\begin{tabular}{ccc}
\hline Stasiun & $\begin{array}{c}\text { Luas } \\
\left(\mathbf{k m}^{2}\right)\end{array}$ & $\begin{array}{c}\mathbf{A i} / \mathbf{A} \\
(\%)\end{array}$ \\
\hline Malakaji & 158,97 & 0,549 \\
\hline Sanrobone & 97,76 & 0,338 \\
\hline Paladingan & 32,58 & 0,113 \\
\hline Jumlah & 289,310 & 1
\end{tabular}

\section{Analisa Curah Hujan Rancangan}

Curah hujan rancangan digunakan tiga metode yaitu Distribusi Log Normal, Metode Gumbell, dan Metode Log Pearson tipe III. Hasil dari Ketiga metode tersebut dapat dilihat pada Tabel 3.

Tabel 3 : Rekapitulasi curah hujan rancangan

\begin{tabular}{ccccc}
\hline No. & $\begin{array}{c}\text { Kala } \\
\text { Ulang }\end{array}$ & $\begin{array}{c}\text { Distribusi } \\
\text { Gumbel } \\
\text { Tipe I }\end{array}$ & $\begin{array}{c}\text { Distribusi } \\
\text { Log } \\
\text { Normal 2 } \\
\text { Paramete } \\
\mathbf{r}\end{array}$ & $\begin{array}{c}\text { Distribusi } \\
\text { Log } \\
\text { Pearson } \\
\text { Tipe III }\end{array}$ \\
\cline { 2 - 5 } & $($ thn $)$ & $(\mathrm{mm})$ & $(\mathrm{mm})$ & $(\mathrm{mm})$ \\
\hline $\mathbf{1}$ & 2 & 65,961 & 65,659 & 65,713 \\
\hline $\mathbf{2}$ & 5 & 86,622 & 84,123 & 84,181 \\
\hline $\mathbf{3}$ & 10 & 100,300 & 96,300 & 96,214 \\
\hline $\mathbf{4}$ & 20 & 113,425 & 107,978 & 108,754 \\
\hline $\mathbf{5}$ & 25 & 117,587 & 101,874 & 111,452 \\
\hline $\mathbf{6}$ & 50 & 130,409 & 123,904 & 122,849 \\
\hline $\mathbf{7}$ & 100 & 143,137 & 144,233 & 134,202 \\
\hline $\mathbf{8}$ & 200 & 155,819 & 200,698 & 145,677 \\
\hline
\end{tabular}

\section{Uji Kesesuaian Distribusi}

Untuk menguji kecocokan suatu distribusi sebaran curah hujan, digunakan metode Chi Square dan Smirnov-Kolmogorof.

Berikut hasil uji kesesuaian distribusi untuk metode Gumbel, metode Log Pearson III dan metode Log Normal.

Tabel 4. Hasil kesesuaian distribusi

\begin{tabular}{cccc}
\hline $\begin{array}{c}\text { Metode } \\
\text { Distribusi }\end{array}$ & $\Delta$ Maks & $\Delta$ Kritis & Ket \\
\hline $\begin{array}{c}\text { Distribusi } \\
\text { Gumbel } \\
\text { Tipe I }\end{array}$ & 0,0819 & 0,2617 & + \\
\hline $\begin{array}{c}\text { Distribusi } \\
\text { Log } \\
\text { Normal 2 } \\
\text { Parameter }\end{array}$ & 0,3799 & 0,2617 & - \\
\hline $\begin{array}{c}\text { Distribusi } \\
\text { Log }\end{array}$ & 0,4360 & 0,2617 & - \\
$\begin{array}{c}\text { Pearson } \\
\text { Tipe III }\end{array}$ & & & \\
\hline
\end{tabular}

Berdasarkan Tabel 4, dari ketiga metode yang digunakan untuk menghitung curah hujan rencana dengan metode Distribusi log pearson III dan metode distribusi Gumbel yang memenuhi persyaratan yaitu nilai maksimum tidak melebihi nilai kritis. Sehingga dari uji kesesuaian distribusi curah hujan rencana metode Gumbel yang digunakan karena berdasarkan uji chi square dan smirnov kolmogorov hanya metode Gumbel yang memenuhi syarat keduanya.

\section{Perhitungan Banjir Rancangan}

Untuk menghitung banjir rancangan menggunakan metode HSS Gama-I , perlu diketahui parameter parameter DAS . Parameter DAS dapat dilihat pada Tabel 5. 
Tabel 5 : Parameter perhitungan hidrograf

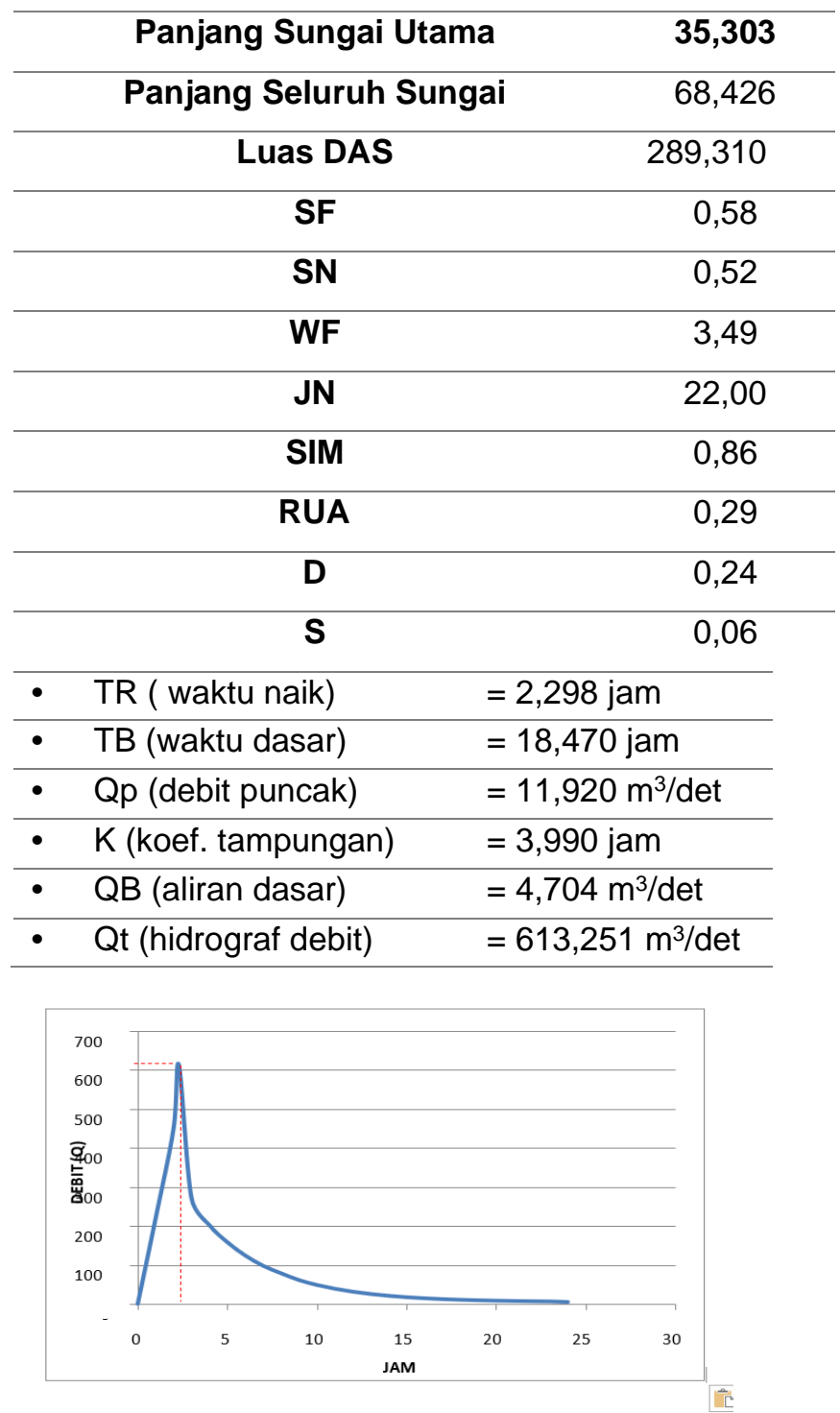

Gambar 2. Grafik perhitungan HSS Gama I

Dari Gambar 2 diketahui hasil perhitungan hidrograf dengan debit puncak sebesar 613,251 $\mathrm{m}^{3}$ /detik terjadi pada jam ke 2,298.

\section{Perencanaan Spillway}

a. Penentuan Type

Pada perencanaan ini digunakan dimensi yang sudah ada pada perencanaan sebelumnya mulai dari lebar spillway, tinggi mercu, elevasi mercu, tinggi energy di atas mercu hingga diameter mercu. Perencanaan ini dicoba dengan menggunakan debit banjir rancangan periode ulang yang berbeda dari perencanaan sebelumnya juga dicoba menggunakan tipe mercu yang berbeda, tipe mercu yang digunakan pada perencanaan sebelumnya menggunakan tiper mercu ogee dan pada perencanaan ini dicoba dengan menggunakan tipe mercu bulat yang nantinya akan didapatkan tinggi energi di atas mercu berdasarkan debit banjir rancangan yang telah ditentukan.

\section{b. Perencanaan Dimensi Spillway}

Perencanaan spillway ini dibuat untuk mendapatkan suatu perbandingan apabila dibuat suatu perencanaan yang berbeda dengan perencanaan sebelumnya, pada perencanaan akan digunakan beberapa persamaan dimensi pada perencanaan sebelumnya diantaranya lebar spillway 30 meter dan elevasi mercu +248,50. Perencanaan ini dibuat menggunakan debit banjir rancangan periode ulang 200 tahun ( $Q_{200}$ ) dengan tipe mercu bulat.

\section{Menghitung Tinggi $\mathrm{H}_{1}$ Pada Spillway Mercu Bulat}

Untuk mendapatkan nilai tinggi $\mathrm{H}_{1}$ pada Spillway Mercu Bulat dapat dilakukan dengan metode Trial and Error terhadap $\mathrm{H}_{1}$. Hasil perhitungan dapat dilihat pada Tabel 6.

Tabel 6. Perhitungan tinggi $\mathrm{H}_{1}$ pada spillway bermercu bulat

\begin{tabular}{|c|c|c|c|c|}
\hline $\mathbf{H}$ & $\mathbf{C d}$ & $\mathbf{B}$ & $\mathbf{g}$ & $\mathbf{Q}$ \\
\hline 0 & $\mathbf{1 , 4}$ & 30 & 19,62 & 0 \\
\hline 1 & 1,4 & 30 & 19,62 & 124,025 \\
\hline 1,5 & 1,4 & 30 & 19,62 & 227,848 \\
\hline 2 & 1,4 & 30 & 19,62 & 350,794 \\
\hline $\mathbf{2 , 9 0 2}$ & $\mathbf{1 , 4}$ & $\mathbf{3 0}$ & $\mathbf{1 9 , 6 2}$ & $\mathbf{6 1 3 , 1 3 2}$ \\
\hline 3 & 1,4 & 30 & 19,62 & 644,450 \\
\hline
\end{tabular}

Setelah didapatkan hasil perhitungan antara Tinggi $\mathrm{H}_{1}$ pada mercu bulat maka selanjutnya dibuat grafik hubungan antar tinggi $\mathrm{H}_{1}$ dan debit $\mathrm{Q}$.

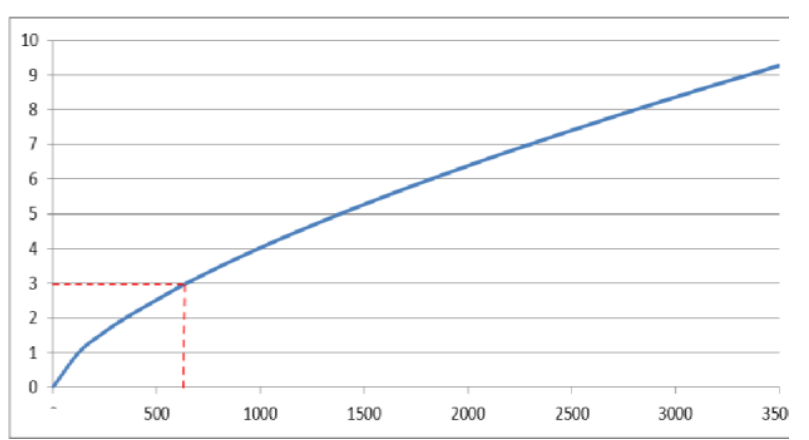

Gambar 4 : Hubungan Antara Tinggi $\mathrm{H}_{1}$ Dan Debit $\mathrm{Q}$ Mercu Bulat.

Dari Gambar 4 menunjukkan grafik hubungan antar tinggi $\mathrm{H}_{1}$ dengan debit $\mathrm{Q}$ yang telah ditentukan, dimana $\mathrm{H}_{1}$ sebesar 2,902 $\mathrm{m}$ dengan ketentuan debit sebesar $613,251 \mathrm{~m}^{3} /$ det.

\section{Pembahasan}

Tinggi $\mathrm{H}_{1}$ pada Spillway sebesar 2,902 meter. Dalam perencanaan ini digunakan debit banjir rencana yang 
berbeda dengan mercu pelimpah yang berbeda., perencanaan sebelumnya menggunakan tipe mercu ogee dan perencanaan ini perencanaan sebelumnya juga menggunakan 3 stasiun namun pada perencanaan sebelumnya dengan perencanaan ini memiliki stasiun hujan yang berbeda. Digunakan pula data terbaru sampai tahun 2018.

Luas Cathment yang diperoleh lebih besar 289,310 $\mathrm{km}^{2}$ dibanding luas catchment area pada perencanaan sebelumnya sebesar $287 \mathrm{~km}^{2}$ perbedaan ini diakibatkan karena perbedaan bentuk catchment juga stasiun hujan yang digunakan.

Metode yang digunakan untuk menghitung curah hujan rancangan yaitu Metode Gumbel, Log Pearson III, dan Log Nomal. Berdasarkan uji kesesuain distribusi chi square dan smirnov-kolmogorof, yang memenuhi metode Gumbel.

Debit Banjir Rancangan Debit banjir maksimum pada lokasi Spillway Bendungan Karalloe sebesar 613,251 $\mathrm{m}^{3} /$ det berbeda dengan perencanaan sebelumnya sebesar $603 \mathrm{~m}^{3} /$ det. Perbedaan disebabkan oleh data curah hujan dan luas tangkapan hujan yang berbeda.

Tipe mercu yang digunakan pada perencanaan sebelumnya adalah tipe Ogee sementara data tinggi energi di atas mercu sebesar 3,80 m sedangkan pada perencanaan ini dicoba dengan menggunakan tipe mercu yang berbeda yaitu mercu bulat sehingga didapatkan tinggi $\mathrm{H}_{1}$ sebesar 2,902 $\mathrm{m}$.

Perbedaan ini dikarenakan beberapa faktor pembeda yaitu dari segi tipe mercu serta nilai koefisien debitnya.

\section{KESIMPULAN}

Berdasarkan hasil perhitungan debit banjir rancangan dengan menggunkan Metode Hidrograf Satuan Sintesis Gama I diperoleh debit banjir rancangan sebesar $613,251 \mathrm{~m}^{3} /$ det.

Lebar spillway diperoleh 30 meter dengan elevasi mercu $+248,50$ meter. Dengan tinggi aliran di atas mercu sebesar $2,902 \mathrm{~m}$.

\section{DAFTAR PUSTAKA}

[1] D. E. Victory, 2016, "Kajian Lebar Bangunan Pelimpah Tipe Lengkung Terhadap Elevasi Muka Banjir,"J. Online Mahasiswa Fakultas Teknik. vol. 3, no. 2, p. 8.

[2] M. S. Jalaludin, M. Taufiq, and P. T. Juwono, 2017,"Studi Perencanaan Spillway Bendungan Loea Kabupaten Kolaka Timur Provinsi Sulawesi Tenggara," J. Mahasiswa Jurusan Teknik Pengairan, vol.1, no.1, p.1-12.2017.

[3] S. S. Saleh, R. Musa, dan H. As'ad, 2019, "Kajian Karakteristik Aliran Terhadap Bangunan Pelimpah Pada Saluran Terbuka."J. Teknik Hidro vo.12, no.2, p.40 - 52.

[4] G. P. Putra dan Y. E. Kumala, 2019. "Evaluasi Kapasitas Spillway Bendungan Darma sebagai Salah Satu Dasar dari Aspek Keamanan Bendungan." Reka Racana J. Teknik Sipil. p.31-38. 